\title{
COMPARISON OF DIFFERENT EXTRACTION TECHNIQUES FOR THE EVALUATION OF POLYPHENOLS CONTENT IN SUMMER SAVORY EXTRACTS
}

\author{
DORINA CASONI ${ }^{\mathrm{a}}$, NELI OLAH $^{\mathrm{b}, \mathrm{c}}$, LOREDANA SORAN ${ }^{\mathrm{d}}$ \\ SIMONA CODRUTA AURORA COBZAC ${ }^{\text {* }}$
}

\begin{abstract}
Efficiency of conventional solvent extraction (maceration and normal refluxing) and novel extraction techniques (ultrasound-assisted extraction-UAE and microwave-assisted extraction-MAE) were compared in order to obtain an enhanced content of total flavonoid, total phenolic compounds and rosmarinic acid from the Satureja hortensis L. (Summer savory) herb. Different mixtures of ethanol-water ratio were used for extraction of these compounds from dry plant material. High level of total flavonoid content was determined for a solvent system consisted of $40 \%$ respectively $50 \%$ ethanol (extraction systems ES6 and ES5) while the most efficient techniques were normal refluxing $(\mathrm{R})$ and ultrasound-assisted extraction when sweep mode (UAE1) was selected. For the same solvent systems (ES6 and ES5), a high content of total phenolic compounds was determined when the normal refluxing $(R)$ and microwave-assisted extraction (MAE1, with a duty coefficient of $40 \%$ and microwave action time1 $\mathrm{min}$ ) were used for the extraction procedure. For the rosmarinic acid extraction, the maceration technique (M) combined with an ethanol-water system consisted of $60 \%$ ethanol (ES4) was found as the most efficient procedure.
\end{abstract}

Keywords: Satureja hortensis L., flavonoids, phenolic compounds, rosmarinic acid, maceration, reflux extraction, ultrasound assisted extraction, microwave assisted extraction

\footnotetext{
${ }^{a}$ Babeş-Bolyai University, Faculty of Chemstry and Chemical Engineering 11 Arany Janos Street, RO-400028, Cluj-Napoca, Romania

${ }^{b}$ PlantExtract, Radaia, Cluj-Napoca, Romania

${ }^{c}$ Vasile Goldiș Western University from Arad, Faculty of Pharmacy, 86 L. Rebreanu Street, 310414 Arad, Romania

${ }^{d}$ National Institute for Research and Development of Isotopic and Molecular Technologies, 65-103 Donath Street, 400293, Cluj-Napoca, Romania

*Corresponding author: codruta.cobzac@yahoo.com
} 


\section{INTRODUCTION}

Summer savory or Garden savory (Satureja hortensis L.), a widely used culinary herb belonging to the Lamiaceae family, has been used as spice for food flavouring and as traditional medicinal tea as remedy to treat various diseases and their symptoms [1]. The most recent studies suggest that the use of some savory species, are effective in body protecting against oxidative stress, free radical damage, inflammation or microbial infections, providing a natural prevention or treatment for some chronic and serious illnesses such as cancer, diabetes, cardiovascular and Alzheimer's diseases [2-5].

Many species of the Lamiaceae family are reported as plants with high content of phenolic compounds and antioxidant capacities [6]. Extensive studies on different Satureja species carried out in the last years demonstrated a remarkable diversity of classes of compounds such as volatile oils, polyphenolic acids, flavonoids - especially derivatives of apigenin and luteolin, tannins, steroids and pyrocatechols existing into [7, 8]. The major components of the essential oils of Satureja species are carvacrol, thymol, phenols [1] while the rosmarinic acid was found to be the major component of the alcoholic extracts [9].

Separation, identification and quantification of flavonoids and phenolic compounds in various Laminaceae family plants (including Savory species) are based especially on chromatographic techniques [10-13]. Most of the extraction procedures of these compounds are based on solvent extraction which is efficient, easy to use and have a wide applicability [14]. The type of the solvents and the composition of the used extraction system is one of the most influential variables on both extraction yield and classes of extracted constituents. Methanol, ethanol, and water are widely employed for extracting different classes of phenols. Despite methanol exhibits the highest capacity to extract polyphenols [15], due to its toxicity is less preferred than ethanol-water mixtures. Studies on extraction of natural antioxidants proved that the ethanol-water mixtures are suited to penetrate the hydrophobic areas of the vegetal matrix facilitating further extraction processes [16, 17]. Methods used for extracting phenolic compounds include both conventional techniques (maceration, reflux) and alternative one using high pressure solvents or the benefits of ultrasounds or microwaves $[12,18]$.

In context of abound studies on volatile oil of Satureja hortensis $L$ existing in scientific literature, the aim of this study is to evaluate the effectiveness of different extraction techniques and systems with respect to the total content of flavonoids, phenolic compounds and rosmarinic acid to obtain high quality hydroalcoholic extracts from the Summer savory cultivated in Romania. 


\section{RESULTS AND DISCUSSION}

Conventional solvent extraction and some of the novel extraction procedures have been used for the flavonoids, phenolic compounds and rosmarinic acid extraction from dry Satureja hortensis $L$. herb.

Based on the consideration that extraction solvent composition is one of the most influential variables on both extraction yield and classes of extracted compounds, various ethanol-water mixtures (ES1-ES6) were investigated. The evaluation of the applied extraction procedures was made based on extracted content of total flavonoids, phenolic compounds and rosmarinic acid content determined by UV-Vis absorption spectrometry and high performance liquid chromatography respectively.

\section{Evaluation of total flavonoids}

The concentration of flavonoids in hydroalcoholic extracts was determined based the rutoside calibration curve $Y=1.9372 x+0.0043$ $\left(R^{2}=0.9990 ; \quad L O D=0.6072 \mu \mathrm{g} / \mathrm{mL} ; \mathrm{LOQ}=1.202 \mu \mathrm{g} / \mathrm{mL}\right)$ on $20 \mu \mathrm{g} / \mathrm{mL}-400$ $\mu \mathrm{g} / \mathrm{mL}$ working range.

Table 1. Total flavonoids content expressed in rutoside $(\mu \mathrm{g} / \mathrm{mL})$ determined in Satureja hortensis L. extracts

\begin{tabular}{|c|c|c|c|c|c|c|}
\hline \multirow{3}{*}{$\begin{array}{c}\text { Extraction } \\
\text { procedure }\end{array}$} & \multicolumn{5}{|c|}{ Total flavonoids expressed as rutoside* $(\mu \mathrm{g} / \mathrm{mL}$ extract) } \\
\cline { 2 - 7 } & \multicolumn{5}{|c|}{ Extraction system composition ethanol-water $(\mathrm{v} / \mathrm{v})$} \\
\cline { 2 - 7 } & $100: 0$ & $80: 20$ & $70: 30$ & $60: 40$ & $50: 50$ & $40: 60$ \\
& $(\mathrm{ES} 1)$ & $(\mathrm{ES} 2)$ & $(\mathrm{ES} 3)$ & $(\mathrm{ES} 4)$ & $(\mathrm{ES} 5)$ & $(\mathrm{ES6})$ \\
\hline $\mathrm{M}$ & 13.66 & 77.9 & 113.40 & 125.04 & 129.53 & 108.57 \\
& $( \pm 7.4)$ & $( \pm 3.6)$ & $( \pm 2.3)$ & $( \pm 1.3)$ & $( \pm 2.1)$ & $( \pm 1.1)$ \\
\hline $\mathrm{R}$ & 15.44 & 99.28 & 128.45 & 143.08 & 149.55 & 151.49 \\
& $( \pm 6.4)$ & $( \pm 3.9)$ & $( \pm 1.9)$ & $( \pm 3.1)$ & $( \pm 2.4)$ & $( \pm 0.2)$ \\
\hline UAE1 & 9.34 & 83.87 & 134.72 & 147.37 & 152.63 & 151.65 \\
& $( \pm 4.0)$ & $( \pm 4.1)$ & $( \pm 2.6)$ & $( \pm 2.6)$ & $( \pm 2.1)$ & $( \pm 2.2)$ \\
\hline UAE2 & 10.76 & 88.72 & 122.41 & 132.60 & 136.27 & 128.81 \\
& $( \pm 4.1)$ & $( \pm 3.7)$ & $( \pm 3.9)$ & $( \pm 1.5)$ & $( \pm 1.9)$ & $( \pm 1.3)$ \\
\hline MAE1 & 9.42 & 51.06 & 79.14 & 118.84 & 142.57 & 141.56 \\
& $( \pm 5.9)$ & $( \pm 4.2)$ & $( \pm 2.7)$ & $( \pm 3.1)$ & $( \pm 2.3)$ & $( \pm 1.3)$ \\
\hline MAE2 & 12.98 & 45.97 & 107.64 & 128.58 & 140.14 & 1.38 .02 \\
& $( \pm 4.7)$ & $( \pm 3.9)$ & $( \pm 3.2)$ & $( \pm 2.7)$ & $( \pm 3.1)$ & $( \pm 1.4)$ \\
\hline MAE3 & 13.37 & 68.46 & 106.07 & 116.86 & 140.63 & 134.62 \\
& $\pm(8.2)$ & $( \pm 2.5)$ & $( \pm 3.7)$ & $( \pm 2.2)$ & $( \pm 1.9)$ & $( \pm 2.6)$ \\
\hline
\end{tabular}

* results are mean of three experimental determinations \pm relative standard deviation value; M maceration; R - normal refluxing; UAE1 - ultrasound assisted extraction (sweep mode); UAE2 ultrasound-assisted extraction (clean mode); MAE1-microwave-assisted extraction: duty coefficient 40\%, 1 min microwave action time; MAE2 - microwave-assisted extraction: duty coefficient $40 \%, 2$ min microwave action time; MAE3 - microwave-assisted extraction: duty coefficient $60 \%, 1$ min microwave action time 
The determined total flavonoids content expressed in rutoside, ranged from $11 \mu \mathrm{g} / \mathrm{ml}$ extract to $151 \mu \mathrm{g} / \mathrm{ml}$ extract, depending on the composition of the extraction system and extraction technique (Table 1).

Based on the obtained results it could be observed that for all applied extraction techniques, the flavonoids concentration increases with the polarity of the extraction system. High extraction yields were determined for the ES5 and ES6 (Figure 1). Regarding the extraction techniques, the best extraction yields were obtained using UAE1 due to continues action of ultrasonic waves which contribute to cell membrane breaking and $\mathrm{R}$ due to high extraction temperature that increases the solubility and diffusion coefficient respectively.

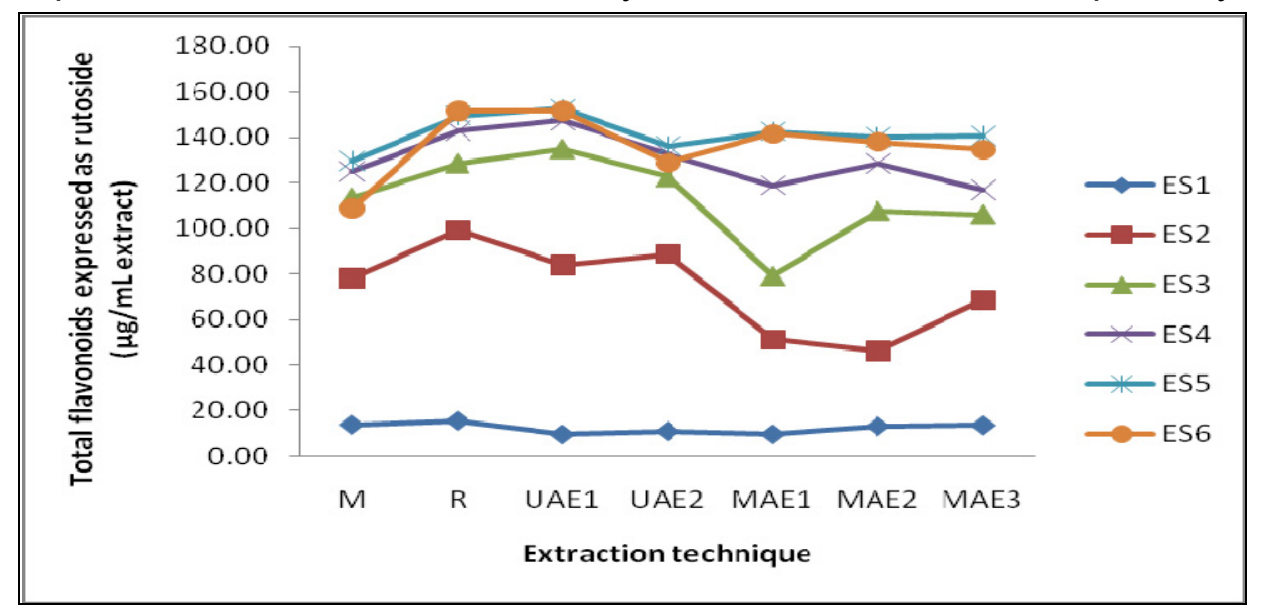

Figure 1. Influence of extraction system composition and extraction technique on total flavonoid content

\section{Evaluation of polyphenols}

Evaluation of polyphenols is based on the caffeic acid calibration curve $\mathrm{Y}=1.245 \mathrm{x}+0.0033 \quad\left(\mathrm{R}^{2}=0.9990 ; \quad \mathrm{LOD}=0.2894 \mathrm{\mu g} / \mathrm{mL} ; \quad \mathrm{LOQ}=0.5571\right.$ $\mu \mathrm{g} / \mathrm{mL}$ ) determined on the $0.05-0.50 \mathrm{mg} / \mathrm{mL}$ working range. The determined values of total polyphenols, expressed in caffeic acid, lies between 0.53 $6.85 \mathrm{mg} / \mathrm{mL}$ extract (Table 2).

The extraction yield of polyphenols is strongly influenced both by the extraction technique and by the extraction system composition (Figure 2 ). Best results were obtained by using ES5 and ES6 systems and R and MAE1 as extraction techniques.

Having a close look to Figure 2 it can be observed that extraction efficiency for R and MAE1 increases with solvent polarity. Moreover for UAE technique, both procedures show a similar trend lines, UAE1 being slightly more efficient. A different situation is encountered in the case of the MAE. Thus, for MAE3 the yield increase with extraction system polarity, from SE1 to SE3 when a maximum yield is obtained, after which the growth of the solvent's polarities 
induce a decrease of the yield. For MAE2 there is an intermediate trend, common with MAE1 in the first part and in the second part common with MAE3.

Table 2. Total polyphenols content, expressed in caffeic acid, determined in Satureja hortensis L. extracts

\begin{tabular}{|c|c|c|c|c|c|c|}
\hline \multirow{3}{*}{$\begin{array}{c}\text { Extraction } \\
\text { procedure }\end{array}$} & \multicolumn{6}{|c|}{ Total polyphenols content expressed as caffeic acid (mg/mL extract) } \\
\cline { 2 - 6 } & \multicolumn{5}{|c|}{ Extraction system composition ethanol-water (v/v) } \\
\cline { 2 - 6 } & $100: 0$ & $80: 20$ & $70: 30$ & $60: 40$ & $50: 50$ & $40: 60$ \\
& $(\mathrm{ES} 1)$ & $(\mathrm{ES} 2)$ & $(\mathrm{ES} 3)$ & $(\mathrm{ES} 4)$ & $(\mathrm{ES} 5)$ & $(\mathrm{ES} 6)$ \\
\hline \multirow{2}{*}{$\mathrm{M}$} & 1.10 & 2.80 & 5.44 & 5.56 & 4.55 & 3.51 \\
& $( \pm 5.8)$ & $( \pm 4.3)$ & $( \pm 3.3)$ & $( \pm 3.5)$ & $( \pm 4.0)$ & $( \pm 5.4)$ \\
\hline $\mathrm{R}$ & 0.98 & 5.70 & 6.28 & 6.36 & 6.56 & 6.85 \\
& $( \pm 3.4)$ & $( \pm 2.8)$ & $( \pm 2.4)$ & $( \pm 3.4)$ & $( \pm 1.4)$ & $( \pm 3.0)$ \\
\hline UAE1 & 0.79 & 5.24 & 5.83 & 5.96 & 6.47 & 5.55 \\
& $( \pm 2.6)$ & $( \pm 3.0)$ & $( \pm 3.1)$ & $( \pm 3.5)$ & $( \pm 3.0)$ & $( \pm 3.6)$ \\
\hline UAE2 & 0.67 & 5.22 & 5.39 & 5.26 & 6.05 & 5.63 \\
& $( \pm 2.4)$ & $( \pm 3.1)$ & $( \pm 2.7)$ & $( \pm 3.1)$ & $( \pm 3.5)$ & $( \pm 6.8)$ \\
\hline MAE1 & 0.53 & 4.40 & 6.06 & 6.48 & 6.59 & 6.71 \\
& $( \pm 3.7)$ & $( \pm 3.5)$ & $( \pm 3.2)$ & $( \pm 2.8)$ & $( \pm 2.5)$ & $( \pm 3.1)$ \\
\hline MAE2 & 0.74 & 4.38 & 5.87 & 5.39 & 5.22 & 4.52 \\
& $( \pm 3.3)$ & $( \pm 14.4)$ & $( \pm 1.6)$ & $( \pm 3.6)$ & $( \pm 4.4)$ & $( \pm 2.5)$ \\
\hline MAE3 & 0.75 & 5.49 & 6.19 & 6.01 & 5.78 & 5.16 \\
& $( \pm 7.5)$ & $( \pm 3.7)$ & $( \pm 3.2)$ & $( \pm 3.3)$ & $( \pm 3.1)$ & $( \pm 5.0)$ \\
\hline
\end{tabular}

* results are mean of three experimental determinations \pm relative standard deviation value $M$ - maceration; R - normal refluxing; UAE1 - ultrasound assisted extraction (sweep mode); UAE2 - ultrasound-assisted extraction (clean mode); MAE1-microwave-assisted extraction: duty coefficient $40 \%$, microwave action time:1 min; MAE2 - microwave-assisted extraction: duty coefficient $40 \%$, microwave action time: 2 min; MAE3 - microwave-assisted extraction: duty coefficient $60 \%, 1$ min microwave action time

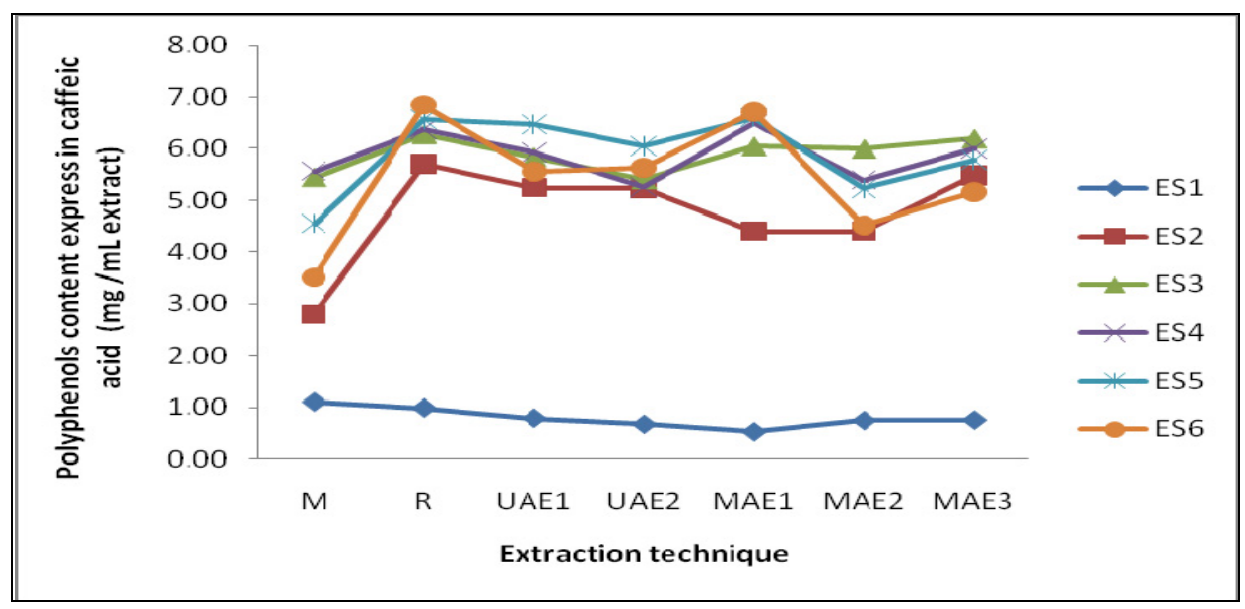

Figure 2. Influence of extraction system composition and extraction technique on total polyphenols content 


\section{Rosmarinic acid determination}

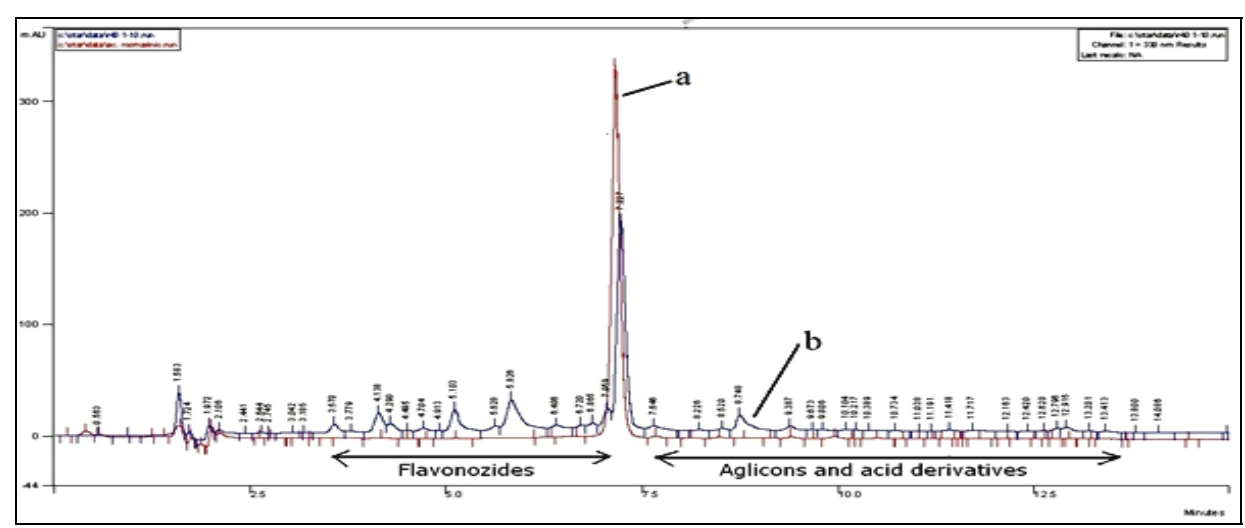

Figure 3. RP-HPLC Chromatogram of rosmarinic acid standard solution (a) and Satureja hortensis L extract obtained by reflux and ES6 (b)

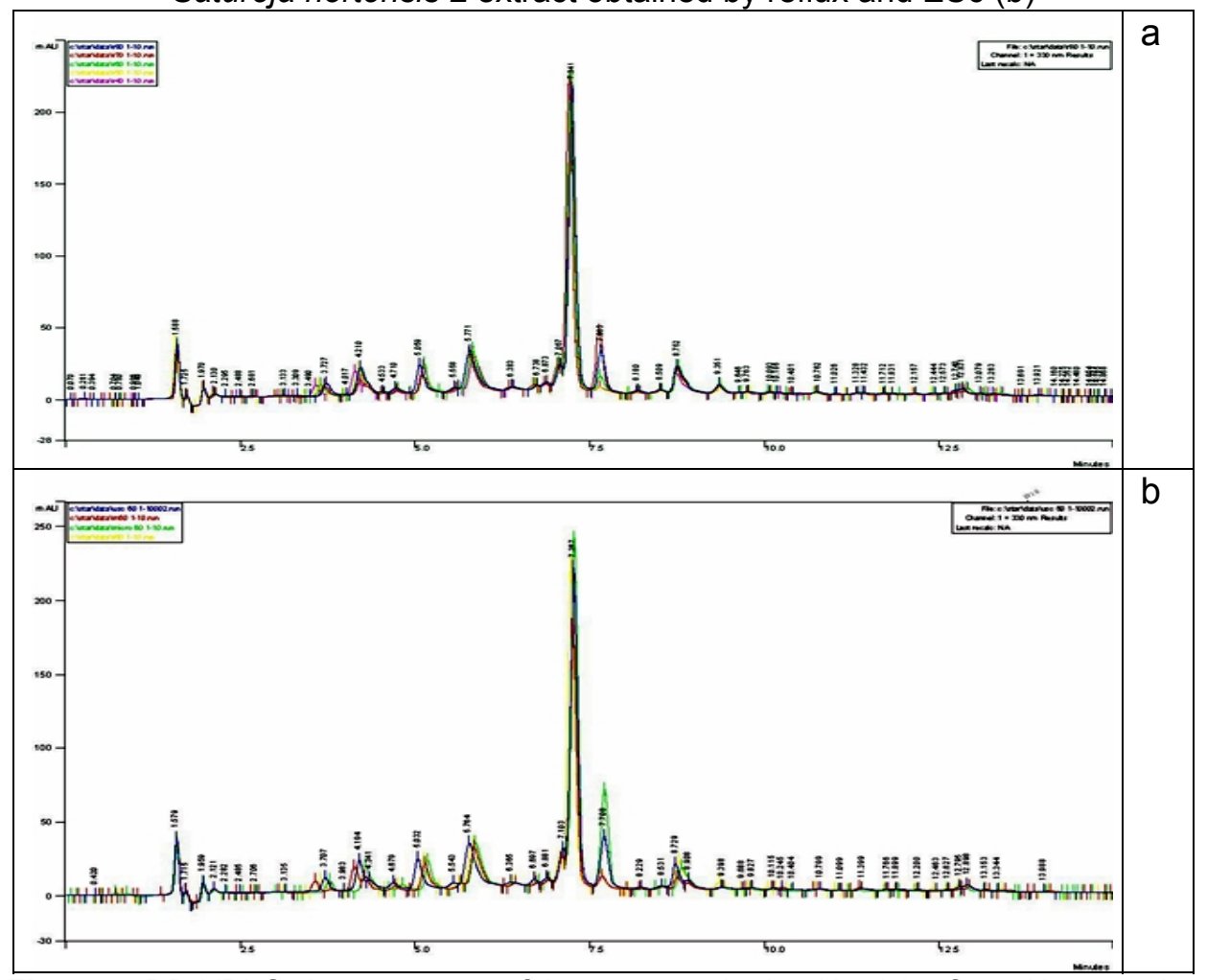

Figure 4. RP-HPLC chromatogram of the extracts obtained by (a) reflux with extraction systems ES2-ES6 and (b) using extraction system ES4 and different techniques - M, R, UAE1 and MAE1. 
Rosmarinic acid separation was performed by RP-HPLC with gradient elution. Its identification in extracts was performed by comparison the retention time $(17.24 \mathrm{~min})$ and UV-spectra with a standard solution (Figure 3).

From qualitative point of view, the chromatograms obtained for the same technique and different extraction systems as well as for the same extraction system and different techniques have the same number of peaks, differing only in the area of peaks (Figure 4).

A linear calibration curve of rosmarinic acid $(Y=179672 x+476900$; $\mathrm{R}^{2}=0.9997$ ) on the working range $25-200 \mu \mathrm{g} / \mathrm{mL}$ was obtained. The content of rosmarinic acid determined in extracts ranged between $50-118$ $\mu \mathrm{g} / \mathrm{mL}$ extract (Table 3).

Table 3. Rosmarinic acid content ( $\mu \mathrm{g} / \mathrm{mL}$ extract) determined in extracts of Satureja hortensis $L$.

\begin{tabular}{|c|c|c|c|c|c|}
\hline \multirow{3}{*}{$\begin{array}{c}\text { Extraction } \\
\text { procedure }\end{array}$} & \multicolumn{5}{|c|}{ Rosmarinic acid content in extracts $(\mu \mathrm{g} / \mathrm{mL})^{*}$} \\
\cline { 2 - 6 } & \multicolumn{5}{|c|}{ Extraction system composition ethanol-water $(\mathrm{v} / \mathrm{v})$} \\
\cline { 2 - 6 } & $80: 20$ & $70: 30$ & $60: 40$ & $50: 50$ & $40: 60$ \\
& $(\mathrm{ES} 2)$ & $(\mathrm{ES} 3)$ & $(\mathrm{ES} 4)$ & $(\mathrm{ES5})$ & $(\mathrm{ES6})$ \\
\hline $\mathrm{M}$ & 75.17 & 108.42 & 152.58 & 143.92 & 50.34 \\
& $( \pm 3.9)$ & $( \pm 3.1)$ & $( \pm 3.6)$ & $( \pm 2.6)$ & $( \pm 3.8)$ \\
\hline $\mathrm{R}$ & 96.35 & 97.43 & 118.15 & 109.25 & 77.84 \\
& $( \pm 2.5)$ & $( \pm 3.3)$ & $( \pm 2.9)$ & $( \pm 2.8)$ & $( \pm 3.6)$ \\
\hline UAE1 & 93.74 & 88.94 & 102.43 & 100.24 & 101.07 \\
& $( \pm 2.8)$ & $( \pm 4.9)$ & $( \pm 3.2)$ & $( \pm 3.1)$ & $( \pm 2.4)$ \\
\hline MAE1 & 81.22 & 102.21 & 102.79 & 101.93 & 100.70 \\
& $( \pm 3.1)$ & $( \pm 2.5)$ & $( \pm 3.4)$ & $( \pm 3.2)$ & $( \pm 2.6)$ \\
\hline
\end{tabular}

* results are mean of three experimental determinations \pm relative standard deviation value; $\mathrm{M}$ - maceration; R - normal refluxing; UAE1 - ultrasound-assisted extraction (sweep mode); MAE1-microwave-assisted extraction: duty coefficient 40\%, 1 min microwave action time

The amount of extracted rosmarinic acid is influenced by the extraction procedure (Figure 5). Thus, the extraction profiles showed that the systems ES4, ES5 and ES6 (in case of UAE1 and MAE1) were most effective and no significant variations due to variations in the ethanol-water ratio for R, UAE1 and MAE1 were observed.

A higher content of rosmarinic acid was determined using systems ES4 and ES5 when maceration was applied as extraction technique. Combination of the maceration technique (M) with the ethanol-water ratio $(60: 40, \mathrm{v} / \mathrm{v})$ extraction system (ES4) was found as the most efficient procedure for extraction of an enhanced amount of rosmarinic acid from dry Satureja hortensis L. plant. 


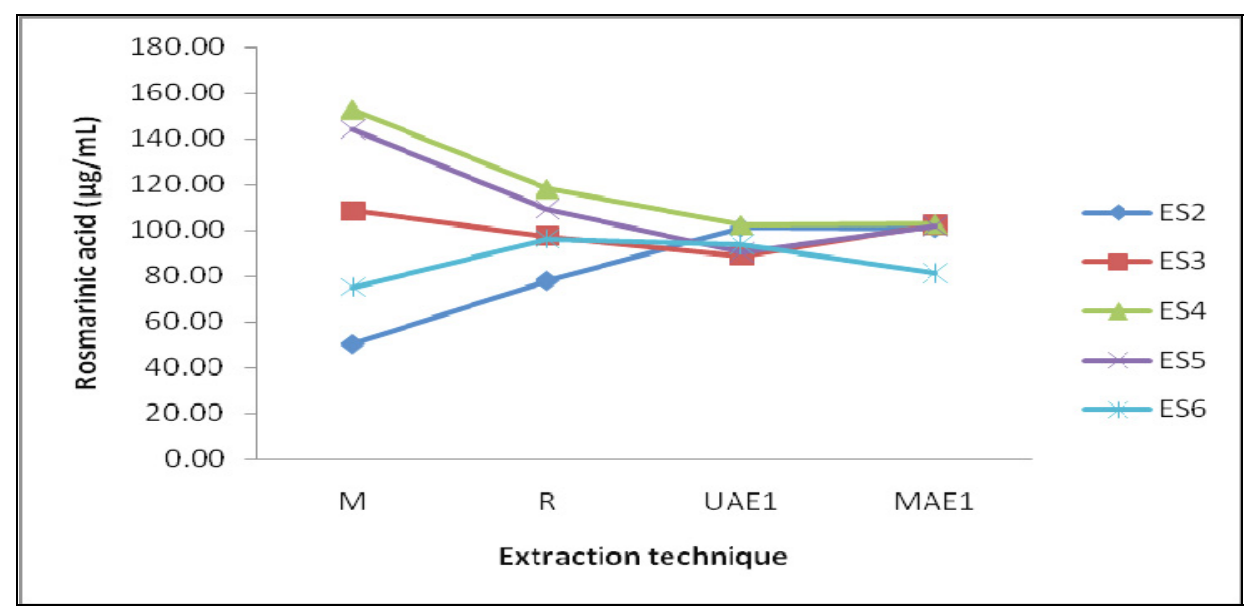

Figure 5. Influence of extraction system composition and extraction technique on rosmarinic acid content

\section{CONCLUSIONS}

Among the solvent extraction techniques investigated in this study, the ultrasound-assisted extraction with sweep mode selection (UAE1) and normal refluxing procedure $(R)$ were found as the most efficient for the total flavonoids extraction from Satureja hortensis L. dry plant material. Normal refluxing $(R)$ and also the microwave-assisted extraction using a duty coefficient of $40 \%$ and 1 minute microwave action time (MAE1) were found as the most suitable procedures for extraction of high content of polyphenolic compounds. For both of the investigated classes of compounds (flavonoids and polyphenols), combination of these techniques with the ethanol-water extraction system consisting of $50-60 \%$ ethanol were found to be the most efficient extraction procedures. Instead of this, the ethanol-water extraction system consisted of $60 \%$ ethanol combined with the maceration technique (M) was found as the most efficient procedure for the extraction of an enhanced content of rosmarinic acid from Satureja hortensis $L$. dry plant material.

\section{EXPERIMENTAL SECTION}

\section{Equipment, reagents and plant material}

The experiments were carried out using a Zass electric mill, a Soxhlet extractor, an Elmasonic $\mathrm{S} 15 \mathrm{H}$ (Germany) ultrasonic bath, a homemade microwave extractor (PATENT H-OSIM NO 6/065 on 30.06.2008, 
INCDTIM, Cluj-Napoca, Romania), a Jasco V 550 UV-Vis spectrophotometer (Japan) and a Varian Prostar HPLC system with quaternary pump, autosampler and DAD detector (Varian, USA). Organic solvents chloroform, ethanol and methanol were purchased from Chemical Company (Romania); acetonitril and acetic acid HPLC grade were from Merck (Germany). Sodium acetate, aluminium chloride, sodium carbonate, sodium tungstenate, sodium molibdate and phosphoric acid reagents were supplied from Merck (Germany). Rutoside, caffeic acid and rosmarinic acid standards were from Merck (Germany). For the experimental determinations, dried leaves of Satureja hortensis L. (Viola Tricolor, Romania) were purchased from local specialized store.

\section{Sample preparation and extraction procedure}

The plant material (dried leaves) was minced with the electrical mill to reduce the particle size and increase the solid-liquid contact surface for the solvent extraction procedure. The obtained powder was sieved and the fraction with the dimension below $400 \mu \mathrm{m}$ was used for further investigations. Prior to the solvent extraction procedure, chlorophylls and fatty compounds were removed from by Soxhlet extraction with chloroform until a colourless extract was obtained. The resulted plant material was dried at room temperature and accurately weighted portions were used for the extraction procedure. The applied conventional extraction methods included both room temperature maceration for 14 days $(M)$ and normal refluxing for 30 min (R). Alternative solvent extraction techniques including the microwaveassisted (MAE) and ultrasound-assisted (UAE) extraction were used as modern extraction procedures. UAE was carried out for $30 \mathrm{~min}$ at $37 \mathrm{kHz}$ and $95 \mathrm{~W}$. There were selected two types of wave action: sweep mode (UAE1) when a uniform ultrasound field was assured and clean mode (UAE2) when a pulsed field was generated. MAE was performed in close vessel with cooling system at atmospheric pressure and bellow $70^{\circ} \mathrm{C}$. The extraction was carried out at $900 \mathrm{~W}$ with different values of duty coefficient and action time (Table 4).

Table 4. The experimental parameters used for the microwave-assisted extraction (MAE) procedure

\begin{tabular}{|c|c|c|c|}
\hline $\begin{array}{c}\text { Duty coefficient } \\
(\%)\end{array}$ & $\begin{array}{c}\text { Microwave action time } \\
(\mathrm{min})\end{array}$ & $\begin{array}{c}\text { Extraction time } \\
(\mathrm{min})\end{array}$ & Symbol \\
\hline 40 & 1 & $1-2$ & MAE1 \\
\hline 40 & 2 & $4-6$ & MAE2 \\
\hline 60 & 2 & $20-25$ & MAE \\
\hline
\end{tabular}


In all cases, different extraction systems consisting of various proportions of ethanol-water (v/v): 100:0 (ES1); 80:20 (ES2), 70:30 (ES3); 60:40 (ES4), 50:50 (ES5) and 40:60 (ES6) were used. A ratio of $0.5: 40$ of dry plant/extraction solvent volume was used each time. The resulted extracts were filtered and used as stock samples for further quantitative investigations. Triplicate samples were obtained for each extraction method.

\section{Evaluation of total flavonoid content}

Total flavonoids content was determined using aluminium chloride method, when a yellowish soluble complex is formed [19]. An aliquot of stock sample was 1:5 diluted with methanol. Volume of $1 \mathrm{ml}$ of diluted extract was mixed with $1.5 \mathrm{ml}$ sodium acetate $(100 \mathrm{~g} / \mathrm{L})$ and $2.5 \mathrm{ml}$ aluminium chloride $(25 \mathrm{~g} / \mathrm{L})$ and brought with methanol up to $10 \mathrm{ml}$ (volumetric flask). After 15 minutes, the absorbance was measured at 430 $\mathrm{nm}$, using a blank solution prepared from $1 \mathrm{ml}$ diluted extract, $5 \mathrm{ml}$ water and methanol up to $10 \mathrm{ml}$. The total flavonoids content was calculated based on calibration curve, the results being expressed as rutoside $(\mu \mathrm{g} / \mathrm{mL}$ plant extract). Calibration curve was determined on the range of $0.02-0.40 \mathrm{mg} / \mathrm{ml}$, using rutoside standard solution prepared in methanol (1 mg/mL).

\section{Evaluation of total polyphenols}

The phenolic content was determined using Folin-Ciocalteau reagent [19]. Briefly, $1 \mathrm{~mL}$ of stock extract was diluted up to $5 \mathrm{~mL}$ with distilled water. Two-hundred microlitres of the obtained extract were mixed with $2 \mathrm{~mL}$ of Folin-Ciocalteau reagent and brought with sodium carbonate $(15 \%)$ up to $10 \mathrm{~mL}$. The absorbance of the coloured blue samples was measured at $715 \mathrm{~nm}$ Calibration curve was determined on the range of $0.05-0.50 \mathrm{mg} / \mathrm{ml}$, using caffeic acid standard solution prepared in methanol $(1 \mathrm{mg} / \mathrm{mL})$. The phenolic content was calculated based on the caffeic acid calibration curve and the results were given as total polyphenols expressed in caffeic acid ( $\mathrm{mg} / \mathrm{mL}$ plant extract).

\section{Quantitative analysis of rosmarinic acid by HPLC-DAD}

Rosmarinic acid content was determined by high-performance liquid chromatography (HPLC) method using a Varian ProStar HPLC system equipped with gradient pump unit, DAD detector and 
autosampler (1-100 $\mu \mathrm{L})$. Separation was achieved using a Microsorb-MV $100-5 \mathrm{C} 18(150 \mathrm{~mm} \times 4.6 \mathrm{~mm}, 5 \mu \mathrm{m})$ (Agilent Technologies) analytical column and the mixture acetic acid $(10 \%)$ - acetonitrile - water as mobile phase. Gradient elution (from 10:15:75 (v/v/v) to 10:45:45 (v/v/v) in 10 minutes and 10:45:45 ( $/ \mathrm{v} / \mathrm{v})$ for 5 minutes) at a flow rate of $1.0 \mathrm{~mL} / \mathrm{min}$ at room temperature $\left(25^{\circ} \mathrm{C}\right)$ was carried out. UV detection was performed at $330 \mathrm{~nm}$.

\section{REFERENCES}

1. S. Momtaz, M. Abdollahi, International Journal of Pharmacology, 2010, 6, 454.

2. A. Alizadeh, M. Khoshkhui, K. Javidnia, O. Firuzi, E. Tafazoli, A. Khalighi, Journal of Medicinal Plants Research, 2010, 4, 40.

3. R. Hamidpour, S. Hamidpour, M. Hamidpour, M. Shahlari, M. Sohraby, Journal of Traditional and Complementary Medicine, 2014, 4, 140.

4. A.M. Abd El Tawab, N.N. Shahin, M.M. Abdel Mohsen, Chemico-Biological Interactions, 2014, 224, 196.

5. N. Alonso-Carrillo, M.Á. Aguilar-Santamaría, E.J. Vernon-Carter, R. JiménezAlvarado, F. Cruz-Sos, A. Roman-Guerrero, Industrial Crops \& Products, 2017, 103, 213.

6. W. Yi, H.Y. Wetzstein, Journal of the Science of Food and Agriculture, 2010, 90, 1063.

7. M. Mahmoodreza, K. Forough, T. Hossein, G. Younes, Iranian Journal of Pharmaceutical Sciences, 2012, 8, 277.

8. M.M.J. Saharkhiz, K. Zomorodian, A. Taban, K. Pakshir, K. Heshmati, M.J. Rahimi, Journal of Essential Oil Bearing Plants, 2016, 19, 1984

9. S.E.Moghadam, S.N. Ebrahimi, F. Gafner, J.B. Ochola, M. Hamburger, Industrial Crops and Products, 2015, 76, 892

10. A. Ziakova, E. Brandsteterova, Journal of Liquid Chromatography \& Related Technologies, 2003, 26, 443.

11. G.S. Cétković, A.Mandić, J.M. Cānadanović-Brunet, S.M. Djilas, V.T. Tumbas, Journal of Liquid Chromatography \& Related Technologies, 2007, 30, 293.

12. I. Bros, M.L. Soran, R.D. Briciu, S.C. Cobzac, Journal of Planar Chromatography, 2009, 22, 25.

13. J. Hadian, S.N. Ebrahimi, P. Salehi, Industrial Crops and Products, 2010, 32, 62.

14. J. Dai, R.J. Mumper, Molecules, 2010, 15, 7313.

15. M. Pinelo, P. Del Fabbro, L. Manzocco, M.J. Nuñez, M.C. Nicoli, Food Chemistry, 2005, 92, 109.

16. D.P. Xu, Y. Li, X. Meng, T. Zhou, Y. Zhou, J. Zheng, J.J. Zhang, H.B. Li, International Journal of Molecular Sciences, 2017, 18, 96. 
D. CASONI, N. OLAH, L. SORAN, S. C. A. COBZAC

17. E. Conde, A. Moure, H. Domínguez, J. C. Parajó, "Separation, Extraction and Concentration Processes in the Food, Beverage and Nutraceutical Industries", Woodhead Publishing Limited, 2010.

18. H.K. Kala, R. Mehta, K.K. Sen, R. Tandey, V. Mandal, Trends in Analytical Chemistry, 2016, 85, 140.

19. “Farmacopeea Română”, ed. X, Editura Medicală, București, 1993. 